\title{
Criação de Visual Novels com contexto educacional
}

\section{Creation of Visual Novels with educational context}

\section{COELHO, Fernando Pereira. Graduando em Licenciatura em Computação}

Instituto Federal do Sertão Pernambucano - Campus Petrolina. Rua Maria Luiza de Araújo Gomes Cabral, S/N, João de Deus - Petrolina - Pernambuco - Brasil. CEP: 56.316-686 / Telefone: (87) 2101.4300 / Email: fernandopereira.only@gmail.com

FONSECA, Jaiany da Silva Gomes. Graduanda em Licenciatura em Computação Instituto Federal do Sertão Pernambucano - Campus Petrolina. Rua Maria Luiza de Araújo Gomes Cabral, S/N, João de Deus - Petrolina - Pernambuco - Brasil. CEP: 56.316-686 / Telefone: (87) 2101.4300 / E-mail: nanyscarlett13@gmail.com

ALENCAR, Fernanda Cavalcante de. Doutoranda e Mestre em Ciência dos Materiais Universidade Federal do Vale do São Francisco - Campus Juazeiro. Av. Antônio Carlos Magalhães, 510, Country Club - Juazeiro - Bahia - Brasil. CEP: 48902-300 / Telefone: (74) 2102.7609 / E-mail: nandacvalencar@gmail.com

VIEIRA, Maria do Socorro Tavares Cavalcante. Mestre em Psicologia e professora pedagoga do Campus Petrolina

Instituto Federal do Sertão Pernambucano - Campus Petrolina. Rua Maria Luiza de Araújo Gomes Cabral, S/N, João de Deus - Petrolina - Pernambuco - Brasil. CEP: 56.316-686 / Telefone: (87) 2101.4300 / Email: socorro.tavares@ifsertao-pe.edu.br

\section{RESUMO}

Os jogos digitais na sociedade atual têm um importante papel na educação, sendo utilizados por diversas metodologias de ensino como ferramentas de apoio à aprendizagem. Contudo, não existem jogos específicos para todos os temas tratados na educação básica e superior. Nessa perspectiva, o gênero de jogos digitais visual novel se apresenta como uma solução para a elaboração de conteúdos aplicados a um contexto educacional. Este artigo tem como objetivo relatar a experiência acerca da difusão do conhecimento voltado à criação de jogos digitais, do gênero drama interativo, focados em soluções educativas que proporcionem aprendizagem significativa, através de visual novels. Este trabalho serve como referência para estudantes e professores que desejam criar jogos digitais educativos que abordem temas relacionados ao conhecimento científico/acadêmico.

Palavras-chave: Jogos Educativos, Histórias Interativas, Apoio Pedagógico.

\begin{abstract}
Digital games in today's society have an important role in education, being used by several teaching methodologies as tools to support learning. However, there are no specific games for all topics covered in basic and higher education. In this perspective, the visual novel genre of digital games presents itself as a solution for the creation of contents applied to an educational context. This article aims to report the experience about the dissemination of knowledge aimed at creating digital games focused on educational solutions that provide meaningful learning through visual novels. This work serves as a reference for students and teachers who want to create digital games that address topics related to scientific/academic knowledge
\end{abstract}

Keywords: Educational Games, Interactive Stories, Pedagogical Support. Introdução 
COELHO, F. P.; FONSECA, J. S. G.; ALENCAR, F. C.; VIEIRA, M. S. T. C. Criação de Visual Novels com contexto educacional

Nas últimas décadas, com a consolidação dos computadores e a popularização da internet, as tecnologias da informação e da comunicação (TICS) se tornaram comuns no ambiente escolar como componentes aliados à educação. Entendidas como todos os recursos tecnológicos envolvidos no processamento e transmissão de dados (CASTELLS, 2003), as TICs estão presentes no cotidiano da nova geração, os nativos digitais (PRENSKY, 2001), e são capazes de fomentarem os recursos didáticos, contribuírem para a inclusão digital, bem como proporcionarem a troca de experiências e informações de maneira rápida e eficiente (FARIAS, 2013). A modalidade de ensino EAD (Ensino a Distância) é um exemplo do uso das TICs aplicadas no contexto educacional. Nessa modalidade, é possível recriar um ambiente virtual similar ao real através de recursos tecnológicos como salas virtuais, fóruns, vídeo aulas, slides, ambientes AVA (Ambiente Virtual de Aprendizagem), entre outros (FARIAS, 2013; ALBINO E REINHARD, 1998). Essas novas tecnologias, quando utilizadas como recursos didáticos, tornam-se ferramentas de grande potencial, já que possibilitam a transformação de uma aula ministrada em moldes tradicionais em um espaço interativo e dinâmico, o que pode contribuir de forma significativa no processo ensino-aprendizagem (CARVALHO E SANTOS, 2016).

Inseridos nesse contexto estão os jogos como uma tecnologia educacional. De acordo com Huizinga (2003), um jogo significa entretenimento, submetido a regras que estabelecem a vitória ou a derrota, sendo definido como uma atividade lúdica mais ampla que um fenômeno físico ou reflexo psicológico. Pode ser considerado também um ato voluntário concretizado como evasão da vida real, apresentando tensão expressa sob forma de incerteza e acaso, sem o conhecimento do desfecho (diversos fatores influenciam o resultado, desde as estratégias escolhidas até o ambiente em que está contido). Em relação à utilização de jogos na educação, Tarouco et al. (2004) ressalta que os jogos podem ser eficientes no contexto escolar, pois a absorção do conteúdo se torna mais natural ao mesmo tempo em que são exercitadas as funções mentais e intelectuais do aluno, motivando-o e facilitando o aprendizado.

Dentre as modalidades de jogos existentes, destacam-se os eletrônicos ou digitais, que são atividades lúdicas controladas por um programa de computador. Nessa categoria, estão envolvidas diversas ações limitadas por regras e tomadas decisões, que resultam numa condição final: o resultado. De maneira geral, em tais jogos estão inseridos um universo, um contexto (narrativa), um sistema de desafios e metas e uma determinada representação gráfica (SCHUYTEMA, 2011).

Nessa perspectiva, estão as visual novels, narrativas interativas focadas em um determinado enredo que, segundo Modolo (2017), podem ser descritas como um gênero de jogos eletrônicos no qual ações compartilhadas entre o personagem e o jogador permitem uma relação semelhante aos filmes e livros interativos. De acordo com Alves e Taborda (2015), o gênero é versátil e popular no mercado oriental e segue ganhando espaço no ocidente desde 2010. Os autores, ainda afirmam que, com criatividade e inovação, é possível desenvolver visual novels com conteúdo diversos, para diferentes finalidades, tendo em vista a possibilidade de se adaptar temas e roteiros. Para Alves e Taborda (2015), as visual novels podem também estimular e melhorar o hábito de ler, fazendo com que a leitura dos textos aconteça naturalmente, de forma lúdica e em um ritmo menos cansativo quando comparado a textos não interativos.

A possibilidade de trabalhar esse gênero de jogo no contexto educacional foi o que 
COELHO, F. P.; FONSECA, J. S. G.; ALENCAR, F. C.; VIEIRA, M. S. T. C. Criação de Visual Novels com contexto educacional

fundamentou a realização deste trabalho, cujo objetivo principal foi ensinar o processo de criação de jogos educativos do tipo visual novels à comunidade do IF Sertão-PE (discentes e docentes) e à comunidade externa. O curso foi ministrado na modalidade FIC (Formação Inicial Continuada), com auxílio do motor de jogo Monogatari (Visual Novel Engine), seguindo o modelo metodológico de desenvolvimento sugerido por Santos e Meurer (2016), específico para a criação de visual novels.

\section{Nativos Digitais e a Aprendizagem}

Nas últimas décadas, as tecnologias digitais, direta ou indiretamente, passaram a ser inseridas em diversas situações cotidianas. Como consequência dessa inserção, surgiu a geração de indivíduos nativos tecnológicos/digitais. Para Veen e Vrakking (2009) essa nova geração, "Homo zappiens", aprendeu a lidar com as novas tecnologias desde a infância e cresceu usando múltiplos recursos tecnológicos. Recursos esses que permitiram o controle sobre o fluxo de informações; a união entre comunidades virtuais e reais; e a comunicação e colaboração em rede, de acordo com suas necessidades.

"O Homo zappiens é um processador ativo de informação, resolve problemas de maneira muito hábil, usando estratégia de jogo e sabe se comunicar muito bem. Sua relação com a escola mudou profundamente, [...] o Homo zappiens é digital e a escola é analógica" (VEEN E VRAKKING, 2009). Nesse mesmo contexto, Prensky (2001) descreve o Homo zappiens como um nativo digital ou ainda um "falante nativo" da linguagem digital dos computadores, videogames e da internet. É um indivíduo que está familiarizado com informações a todo instante, acostumado a processar mais de uma tarefa ao mesmo tempo.

Tendo em vista a proximidade dos nativos digitais com os videogames, a utilização dos jogos eletrônicos como uma ferramenta aliada à aprendizagem é "motivadora, divertida e versátil", podendo ser aplicada a basicamente todos os temas (PRENSKY, 2012).

Para Grübel e Bez (2006), os jogos facilitam o processo de ensino-aprendizagem e proporcionam experiências prazerosas, interessantes e desafiantes, transformando-se em uma estratégia de ensino para os educadores, bem como em ricos instrumentos para a construção do conhecimento. Mitchel e Savvil-Smith (2004) completam esses pressupostos afirmando que os jogos colocam o aluno no papel de tomador de decisão e o expõe a níveis crescentes de desafios para possibilitar uma aprendizagem através da tentativa e erro. No entanto, para que os jogos sejam considerados ferramentas educacionais, eles deverão possuir características pedagógicas e didáticas a fim de contribuir com o processo de aprendizado.

\section{Histórias Interativas e as Visual Novels}

Nas histórias interativas, o jogador deve perceber que ele planejou, decidiu e agiu em conjunto com o protagonista, influenciando o rumo do enredo. Não se limitando a tal, a interatividade está ligada ao envolvimento com as aventuras e universos imaginários, onde o espectador é capaz de 
COELHO, F. P.; FONSECA, J. S. G.; ALENCAR, F. C.; VIEIRA, M. S. T. C. Criação de Visual Novels com contexto educacional

gerar alterações e verificar suas consequências, sendo capaz de modificar a realidade apresentada, o que garante ao jogador uma maior imersão no ambiente do jogo (LÈVY, 1998; ALVES, 2008; CRAWFORD, 1982).

Dentro deste contexto, as visual novels são histórias interativas que de acordo com Agos et. al (2013) são usualmente compostas de imagens com textos, sons e músicas para adicionar um efeito dramático ao enredo do jogo.

\section{Monogatari}

A principal ferramenta utilizada neste projeto foi o Monogatari (monogatari.io), definido como um framework (uma abstração que une códigos comuns provendo uma funcionalidade genérica) cuja finalidade é a criação de um visual novel. Em outras palavras, o Monogatari funciona como um motor de desenvolvimento de jogos do tipo visual novel que não exige do usuário o conhecimento de programação de computadores, caracterizando-se como uma ferramenta intuitiva de simples edição.

Imagem 1. Demonstração de jogo criado com Monogatari.io

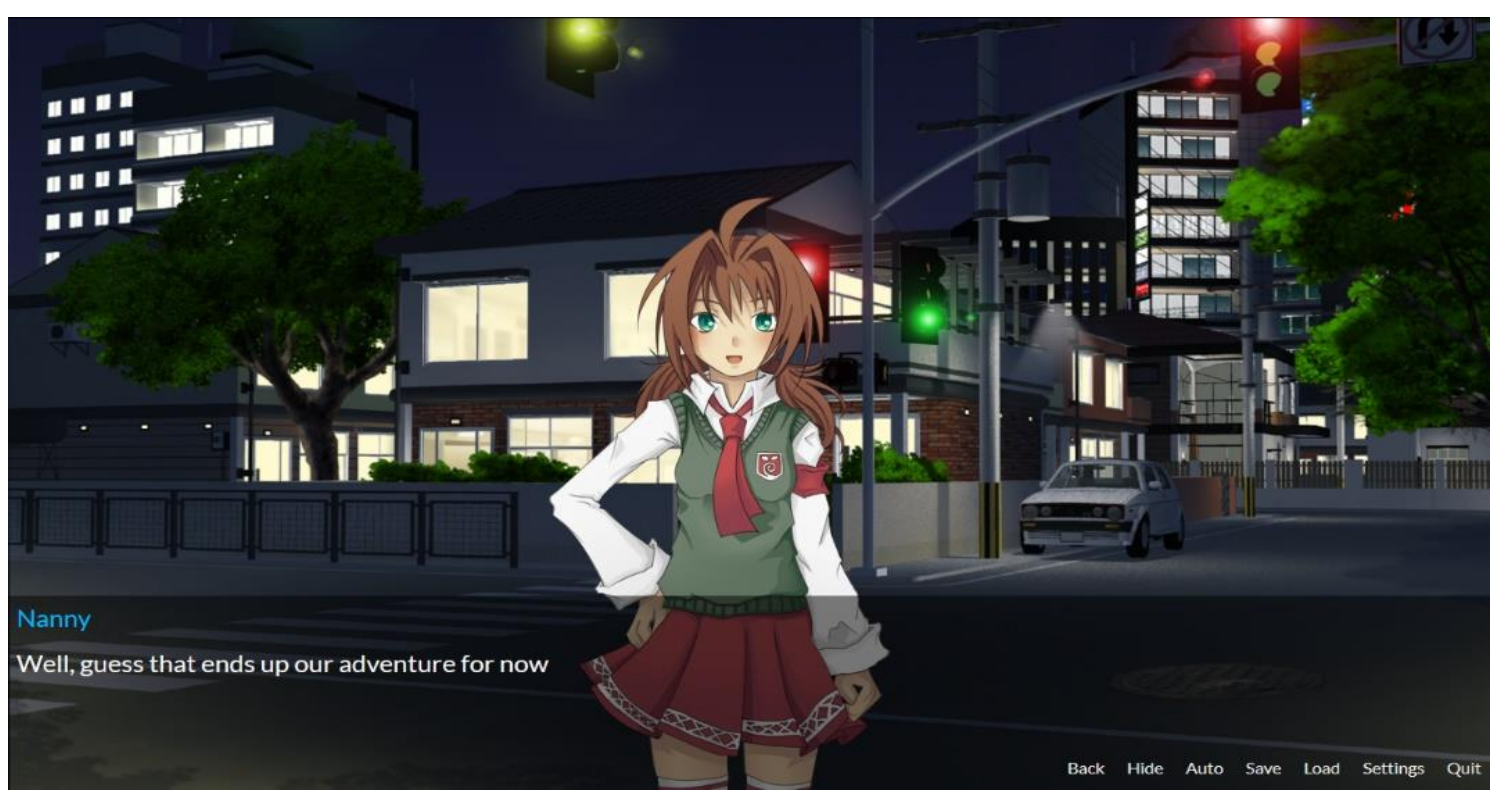

Fonte: Monogatari.io (2020).

O produto final (Imagem 1) é um jogo do gênero visual novel que funciona em diferentes plataformas (multiplataforma), como por exemplo: WEB, executado diretamente do navegador; Desktop, instalado e executado em um computador; e Mobile, instalado e executado através de um aplicativo para smartphone, ficando a critério do criador a forma de distribuí-lo.

O Monogatari foi desenvolvido por Diego Islas Ocampo como um projeto de código aberto lançado sob licença MIT, o que permite sua utilização, modificação e distribuição de maneira gratuita e de forma comercial ou não comercial. A única exigência para utilização desse framework é referenciar o criador nos jogos desenvolvidos. 


\section{Materiais e métodos}

0 projeto foi dividido em três momentos distintos:

1. Primeira etapa (de abril a maio de 2019): construção das estratégias de ensino e de divulgação; e definição das atividades;

2. Segunda etapa (de junho a agosto de 2019): difusão dos conceitos de visual novel e sua aplicação no contexto educacional; e divulgação do curso;

3. Terceira etapa (de setembro a novembro de 2019): seleção de participantes; e aplicação do curso de criação de visual novels em um contexto educacional.

Na primeira etapa, foram realizados um levantamento bibliográfico e a preparação de todo o material necessário para a elaboração do curso utilizando metodologias consolidadas para estratégias de ensino e modelos de aprendizagem.

A metodologia de aprendizagem baseada em projetos (ABP) foi utilizada como principal referência. A ABP foi escolhida por ser um modelo de ensino que permite aos alunos solucionarem questões da realidade, estudando as situações e buscando por soluções eficazes, tornando a aprendizagem significativa (BENDER, 2015). Segundo Ribeiro e Mizukami (2004), a ABP oferece aos alunos um meio de adquirir conhecimentos e desenvolver habilidades, aliando a teoria à prática. Hernandéz e Ventura (1998) ressaltam que essa metodologia contribui na formação de indivíduos com uma visão global da realidade, unindo a aprendizagem a situações e problemas reais.

Ainda na primeira etapa, o método para o desenvolvimento das visual novels foi definido. Escolheu-se a metodologia proposta por Santos e Meurer (2016), específica para criação de jogos do gênero, que descreve os passos a serem seguidos, baseando-se em métodos de desenvolvimento de projetos para facilitar as tomadas de decisões e o gerenciamento de processos (Tabela 1).

Tabela 1. Parâmetros Metodológicos para desenvolvimento de visual novels

\begin{tabular}{|c|c|c|}
\hline Estratégia & Pré-produção & Finalização \\
\hline $\begin{array}{l}\text { Contextualização } \\
\text { - O que é? } \\
\text { - Sinopse; } \\
\text { - Possíveis Alterações }\end{array}$ & 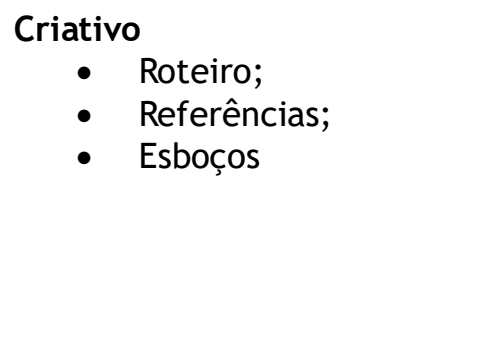 & $\begin{array}{l}\text { Estética } \\
\text { - Identidade vi- } \\
\text { sual; } \\
\text { - Logo e iconogra- } \\
\text { fia; } \\
\text { - Padrão cromá- } \\
\text { tico; } \\
\text { - Tipografia }\end{array}$ \\
\hline $\begin{array}{l}\text { Desconstrução } \\
\text { - } \quad \text { Análise sincrônica; } \\
\text { - Posicionamento gráfico-visual; } \\
\text { - Estrutural, morfológica e fun- } \\
\quad \text { cional; }\end{array}$ & $\begin{array}{l}\text { Estrutura } \\
\text { - Definição de ferra- } \\
\text { mentas; } \\
\text { - Editoração e diagra- } \\
\text { mação; } \\
\text { - Wireframes; }\end{array}$ & $\begin{array}{ll}\text { Execução } \\
\text { • Definição; } \\
\text { • Acabamento; } \\
\text { • Implementação; }\end{array}$ \\
\hline
\end{tabular}

Fonte: Santos e Meurer (2016). 
COELHO, F. P.; FONSECA, J. S. G.; ALENCAR, F. C.; VIEIRA, M. S. T. C. Criação de Visual Novels com contexto educacional

As visual novels foram desenvolvidas utilizando o motor de visual novel Monogatari, os editores de imagem Gimp e Inkscape, o editor de áudio Audacity e os editores de texto Sublime e Notepad++. Todos esses softwares possuem licenças open source ou versões gratuitas para a comunidade. Dessa forma, não houve custos com licenças de softwares para a execução do projeto.

A segunda etapa, por sua vez, foi dividida em dois estágios: a divulgação on-line e a presencial. 0 objetivo dessa etapa foi apresentar à comunidade o conceito de visual novel, destacando aos docentes e discentes a possibilidade de criar ferramentas interativas com os conteúdos abordados nas disciplinas de seus respectivos cursos, e como aplicá-las em sala de aula.

Para a divulgação on-line do edital do curso, da proposta do projeto e dos meios de inscrição, foram utilizados os seguintes canais de comunicação: site próprio, com as principais informações sobre o projeto e o tema abordado (https://aprendendovn.web.app/); redes sociais como Facebook, Instagram e WhatsApp; e o site institucional do IF Sertão-PE.

A divulgação presencial, por sua vez, foi realizada no espaço físico do IF Sertão-PE, Campus Petrolina, através de visitas às salas de aula das turmas do ensino médio e do ensino superior da instituição. Nesse momento, foram apresentadas as principais informações sobre o curso e o tema aos discentes e docentes, sanando eventuais dúvidas.

A terceira etapa consistiu na seleção e aplicação de curso de livre extensão voltado para a criação de visual novels educativas. O curso foi ofertado para alunos e professores do IF Sertão-PE, Campus Petrolina, e para a comunidade externa (indivíduos não vinculados ao IF Sertão-PE), sendo disponibilizado, inicialmente, em duas turmas em dias e horários diferentes com 30 vagas cada. As aulas foram divididas em expositivas e práticas, sendo $25 \%$ da carga horária teórica e $75 \%$ prática, com encontro semanais, totalizando 32 horas.

A seleção foi feita através de um formulário, vinculado ao Edital n²1/2019 da Coordenação Geral de Extensão e Cultura do Campus Petrolina (CGEX), no qual os candidatos manifestaram seu interesse. 0 total de inscrições foi 17, 12 inscritos na primeira turma e 5 inscritos na segunda turma.

O curso foi ministrado de 09/09/2019 a 01/11/2019 no Laboratório de Informática do Campus. Durante esse período, foram realizados encontros semanais, em que foram apresentados, de forma sucinta, os conceitos necessários ao desenvolvimento das visual novels, conforme estrutura pré-definida (ementa). Nesses encontros, os alunos trabalharam individualmente em seus projetos com o auxílio do instrutor.

Cada participante teve a liberdade para criar sua própria história sem tema pré-definido, a única exigência era que houvesse algum contexto educacional incluso, independente da área. Ao final do curso, todos os participantes receberam certificados emitidos pela CGEX e apresentaram os projetos construídos na Semana Nacional de Ciência e Tecnologia (SNCT) do Campus.

\section{Resultados e discussão}

Em um levantamento inicial, realizado durante o período de divulgação do projeto, foi possível perceber o desconhecimento do público acerca dos jogos do gênero visual novel. No decorrer das 
COELHO, F. P.; FONSECA, J. S. G.; ALENCAR, F. C.; VIEIRA, M. S. T. C. Criação de Visual Novels com contexto educacional

visitas às turmas para apresentação da proposta de criação de visual novels no contexto educativo, poucos alunos (cerca de $6.7 \%$ do total) informaram ter conhecimento sobre o gênero.

Dos 17 participantes, 16 eram alunos do IF Sertão-PE (desses, 4 alunos pertenciam ao ensino médio técnico e 8 alunos pertenciam ao ensino superior), e 1 participante (que possuía ensino médio completo) era externo à instituição. Entre os inscritos, apenas 4 tinham um mínimo conhecimento técnico de programação ou desenvolvimento em jogos, mas todos se mostraram motivados em construir suas histórias, com os mais variados motivos e objetivos.

Ao decorrer do curso, foi possível observar que os participantes, mesmo com conhecimento mínimo ou nulo de desenvolvimento de jogos, conseguiram construir, ao menos, um capítulo de seus projetos. O Monogatari se mostrou, de fato, como uma ferramenta simples e eficiente de construção de jogos interativos focados no desenvolvimento do conteúdo/enredo. Esse desempenho se justifica ao observar que framework é dividido em: recursos, a exemplo de áudios (músicas, efeitos sonoros e narrações) e imagens (personagens, cenários/cenas e interface) e script.

No script é onde será construída a visual novel, neste local são arranjados os recursos e o enredo da história. Utilizando um conjunto de instruções através de palavras-chave, é feito o vínculo entre, por exemplo, o recurso e ação no jogo. Essa forma de construir torna o desenvolvimento simples quanto à codificação, já que os criadores precisam aprender apenas essa sintaxe, sem a necessidade de se prenderem aos diversos detalhes da lógica de programação. É importante ressaltar que, caso o criador já tenha domínio de programação, em específico da linguagem Javascript, é possível a adição de elementos de maior complexidade que os utilizados, como minigames e itens.

De maneira geral, diferentes temas foram escolhidos pelos participantes. Uma aluna de Licenciatura em Física iniciou a criação de uma visual novel com foco em apresentar de forma simplificada conceitos sobre física quântica (Imagem 2), apesar de não ter conhecimento sobre linguagem de programação, a aluna conseguiu desenvolver seu projeto de maneira eficiente.

Imagem 2. Apresentação da visual novel "Imersão Cerebral" 


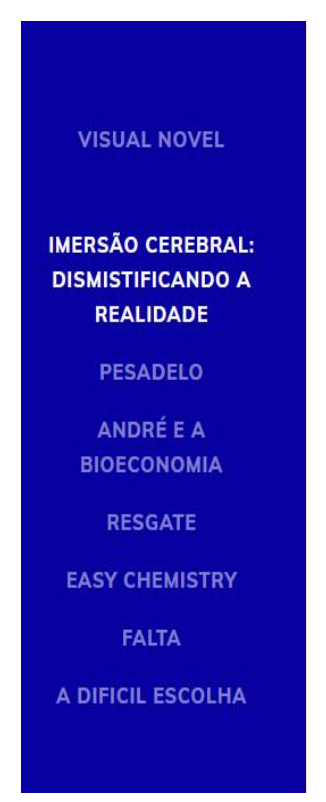

\section{IMERSÃO CEREBRAL: "DISMISTIFICANDO A REALDADE"}

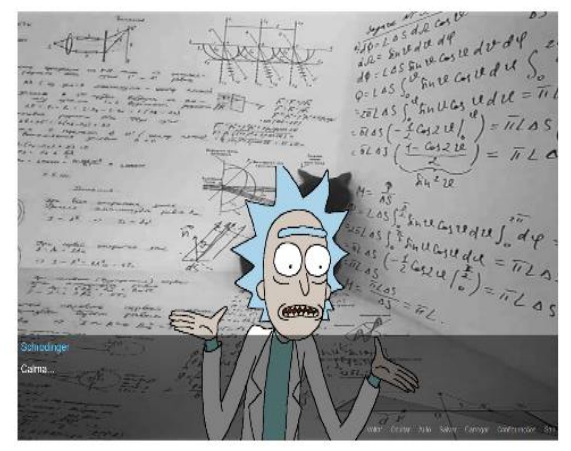

SINOPSE:

Nessa visual novel você irá conhecer (ou relembrar),algumas análises e estudos sobre a realidade que vivemos.Fazendo um passeio pelo "Cérebro de Platão",conhecerá a "Alegoria da Caverna";Fazendo um passeio pelo "Cérebro de Schrödinger",conhecerá um pouco sobre a física quântica,onde foi abordado o experimento teórico conhecido por "Gato de Schrödinger",além de um bônus de imersão cerebral.

Jogar

Fonte: Autores (2020).

Outro exemplo é a visual novel "Easy Chemistry” (Imagem 3), iniciada por um aluno de Licenciatura em Computação, que procura ensinar química utilizando uma estrutura de quizzes, onde as escolhas dos jogadores são temas ou respostas às perguntas que influenciam na progressão da história.

Imagem 3. Apresentação da visual novel "Easy Chemistry”

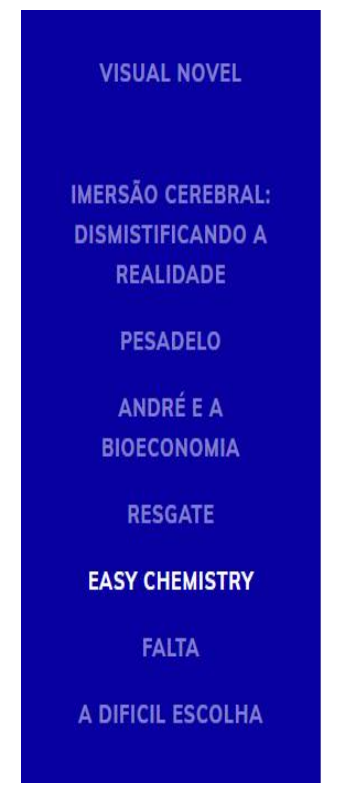

\section{EASY CHEMISTRY}

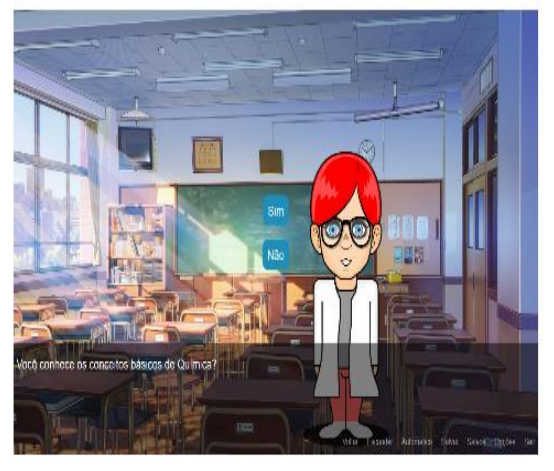

5NOPSE:

Easy Chemistry é um jogo didático onde você aprenderá química por meio de vários exemplos desde os assuntos mais básicos aos mais desafiadores.

Fonte: Autores (2020).

\section{Conclusões}

A criação de visual novels com fins educacionais abre um leque de possibilidades que podem e devem ser exploradas pela comunidade, já que nem sempre é possível aplicar a metodologia de 
COELHO, F. P.; FONSECA, J. S. G.; ALENCAR, F. C.; VIEIRA, M. S. T. C.

Criação de Visual Novels com contexto educacional

aprendizagem baseada em jogos digitais em aula, pois não existem jogos que versem sobre todos os temas das grades curriculares e/ou acompanhe o planejamento do professor.

A criação de visual novel se mostrou como algo relativamente simples, de maneira que o próprio professor pode criar narrativas para aplicar em suas aulas e adaptá-las a outras aulas conforme a sua necessidade (altamente escalável). 0 docente pode, também, incentivar os discentes a criarem suas próprias visual novels utilizando a metodologia de sua preferência. A partir do momento em que os alunos estejam envolvidos no processo de aprendizagem, essa se torna significativa.

As narrativas interativas têm o potencial de alcançar inúmeras pessoas se publicadas on-line, por exemplo. Como é possível abordar diferentes temas, sejam eles educativos ou não, as visual novels podem contribuir de diferentes formas com os seus jogadores (seja acadêmico, social ou emocionalmente), tendo em vista que o funcionamento dessas permite que cada pessoa tenha uma experiência singular.

\section{Referências}

AGOS, C. T. et al. Game Development Of Ibong Adarna Visual Novel. International Journal of Scientific \& Technology Research, v. 2, 2013.

ALBINO, J. P.; REINHARD, N. Uso potencial da tecnologia da informação no ensino de administração. SEMEAD-SEMINÁRIOS EM ADMINISTRAÇÃO, v. 3, 1998.

ALVES, A. G.; TABORDA, P. K. Visual Novel: A evolução do gênero e sua aplicação para desenvolver o hábito da leitura. XIV SBGames - Teresina (PI), 2015.

ALVES, L. Relações entre os jogos digitais e aprendizagem: delineando percurso. Educação, Formação \& Tecnologias, v. 1, n. 2, p. [3-10], 2008.

BENDER, W. N. Aprendizagem baseada em projetos: educação diferenciada para o século XXI. Penso Editora, 2015.

CARVALHO, D. R. S.; SANTOS, V. C. Concepções dos professores sobre a utilização das novas tecnologias (TICs) no processo ensino-aprendizagem da matemática: um estudo na escola pública da rede municipal de ensino de Muritiba-BA. Trabalho de Conclusão de Curso (Graduação em Pedagogia); Faculdade Maria Milza, 2016. Disponível em: <http://131.0.244.66:8082/jspui/bitstream/123456789/164/1/Monografia.pdf >. Acesso em junho de 2020.

CASTELLS, M. A Galáxia da Internet: reflexões sobre a internet, os negócios e a sociedade. Rio de Janeiro: Jorge Zahar, 2003.

CRAWFORD, C. The art of digital game design. Washington State University, Vancouver, 1982.

FARIAS, S. C. Os benefícios das tecnologias de informação e comunicação (TIC) no processo de educação a distância (EAD). RDBCl: Revista Digital de Biblioteconomia e Ciência da Informação, v. 11 , n. 3, p. 15-29, 2013.

GRÜBEL, J. M.; BEZ, M. R. Jogos educativos. Revista Renote Novas Tecnologias da Educação, v 4, ${ }^{\circ}$ 2, dezembro 2006. Disponível em: <https://seer.ufrgs.br/renote/article/download/14270/8183>. Acesso em junho de 2020.

HUIZINGA, J. Homo ludens: o jogo como elemento da cultura. Perspectiva, 5. ed., 2003. 
COELHO, F. P.; FONSECA, J. S. G.; ALENCAR, F. C.; VIEIRA, M. S. T. C. Criação de Visual Novels com contexto educaciona

LÈVY, P. Tecnologias intelectuais e modos de conhecer: nós somos o texto. Tradução de Celso Cândido. Acesso em junho de 2020.

MODOLO, B. R. Manual De Narrativas Interativas. Garoa Fina, 2017. Disponível em: <http://www.garoafina.com.br/pdf/manual_games_garoafina.pdf>. Acesso em 19 Jun. 2020.

PRENSKY, M. "Digital natives, digital immigrants part 1". On the horizon 9.5, p. 1-6, 2001.

PRENSKY, M. Aprendizagem Baseada em Jogos Digitais. São Paulo: Senac, 2012.

RIBEIRO, L. R., MIZUKAMI, M.G.N. A PBL na Universidade de Newcastle: Um Modelo para o Ensino de Engenharia no Brasil? Olhar de Professor. Ano/vol 7, no001, Universidade Estadual de Ponta Grossa, Ponta Grossa, Brasil, 2004.

SANTOS, B. F.; MEURER, H. Parâmetros Metodológicos Para O Desenvolvimento De Visual Novels. In: Anais do $12^{\circ}$ Congresso Brasileiro de Pesquisa e Desenvolvimento em Design. Blucher Design Proceedings, v. 9, n. 2. São Paulo, 2016.

SCHUYTEMA, P. Design de games: uma abordagem prática. São Paulo: Cengage Learning, 2011.

TAROUCO, L. M. R. et al. Jogos educacionais. RENOTE: revista novas tecnologias na educação [recurso eletrônico]. Porto Alegre, RS, 2004.

VEEN, W.; VRAKKING, B. Homo Zappiens: educando na era digital. Porto Alegre: Artmed, 2009. 